\title{
Malraux au Panthéon
}

"L'homme ne devient homme que dans
la poursuite de sa voie la plus haute."

Vingt-trois novembre 1996 : transfert des cendres d'André Malraux au Panthéon. Il prend place parmi les "grands hommes" dont Voltaire, Rousseau, Hugo, Zola, Jean Moulin et son "terrible cortège." La vie de Malraux, déjà célèbre, déjà légendaire, subit encore une métamorphose et atteint une apothéose, une sorte de canonisation dans la religion de 1'Etat, cette "Patrie reconnaissante." Avec cet honneur, on reconnaît le grand écrivain de La Condition humaine, de L'Espoir, des Antimémoires, la haute vision de l'homme d'Etat, la noblesse de son engagement multiple et son humanisme sans compromis.

L'événement est admirablement médiatisé : il y a plusieurs nouvelles publications dont un troisième volume de la Pléiade, de riches dossiers dans les journaux et les revues, de nombreuses émissions à la radio et à la télévision, des expositions, encore un timbre-poste et un colloque international.

A la nuit tombante, les yeux de toute la France sont fixés devant la place du Panthéon où le Président de la République accueille le "grand homme" et lui rend hommage : "Parce que vous avez su faire vivre vos rêves et les faire vivre en nous..." Et Maurice Schumann circonscrit la quintessence de cette grandeur : "C'est l'anti-destin qui franchit ce soir le seuil du Panthéon."

Pendant deux jours, un défilé continu de citoyens coule autour du dôme de l'ancienne église au centre de laquelle repose le cercueil entouré de six gardes républicaines. D'un côté un Giacometti à grands pas figure la route infinie qui s'ouvre devant l'humanité ; d'un autre un grand chat assis évoque à la fois l'intime et le mystérieux de l'existence, conférant, d'ailleurs, un air païen à ce décor stylisé, solennel, sacré.

Et puis Malraux entre encore une fois dans "l'ordre de la Nuit." Le souvenir est inscrit dans les piliers marbrés du Panthéon de la République pour les générations à venir. 
"Il ne fut pas seulement grand comme écrivain, mais comme homme d'action. La conjonction de ses vies fait de lui un homme d'exception," écrit Alain Peyrefitte ( $L e$ Figaro, 23-11-96). Alain Genestar lui fait écho: "Malraux n'est pas réductible. Sa vie, faite d'une addition de vies qui composent une seule grande histoire, va au-delà de ce qui est convenu d'appeler la politique" (Le Journal du Dimanche, 24-11-96). Les témoignages de l'esprit, les sentiments du coeur, abondent : paroles offertes à un homme qui fut, à une vie exemplaire qui symbolise toujours le meilleur qui habite l'homme, sa capacité infinie d'aimer, de lutter, d'espérer.

Sergio Villani

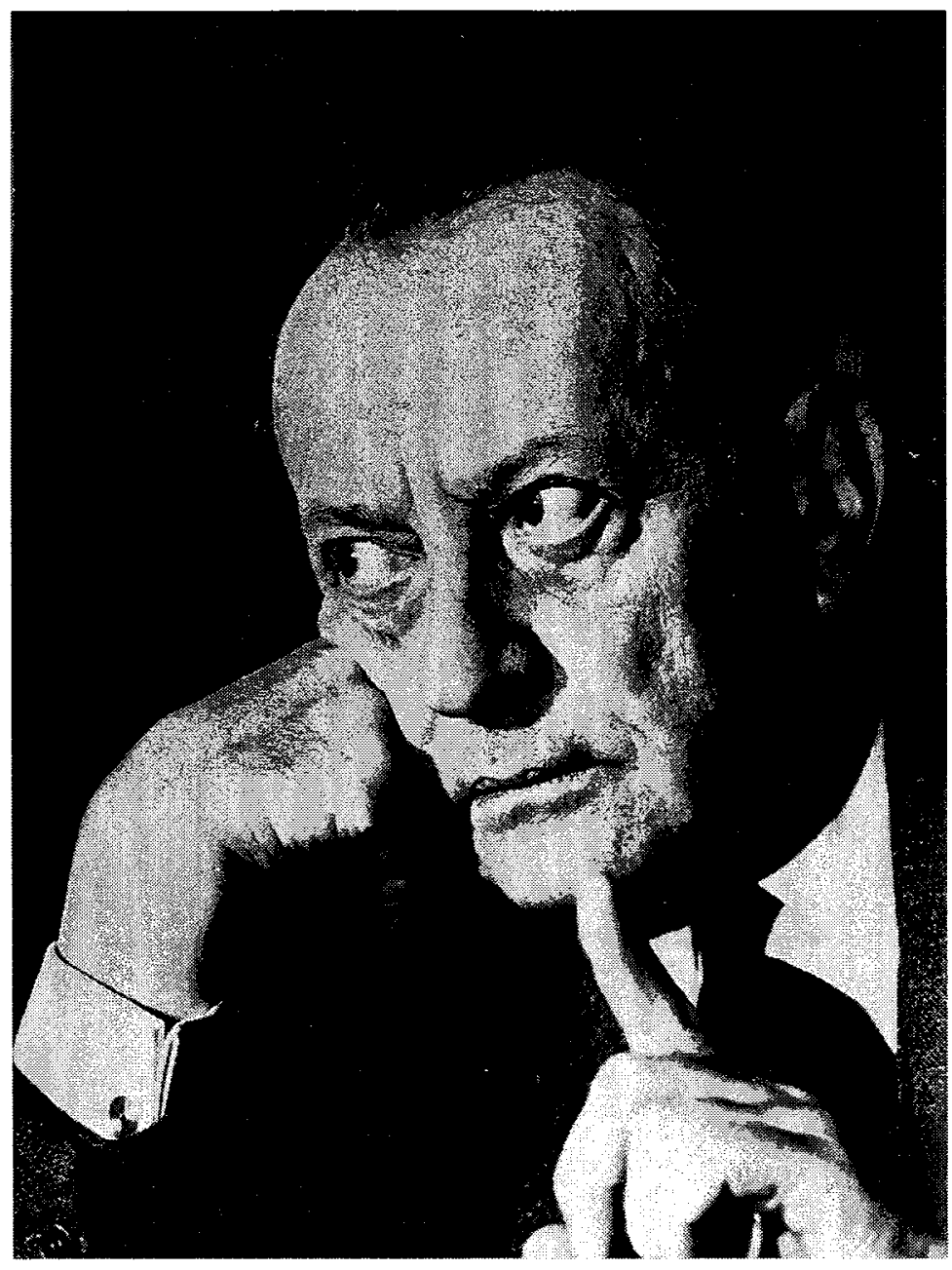

André Malraux (Fond Henriette Colin) 